\title{
Real-World Safety and Effectiveness of Canagliflozin Treatment for Type 2 Diabetes Mellitus in Japan: SAPPHIRE, a Long-Term, Large-Scale Post-Marketing Surveillance
}

\author{
Nobuya Inagaki · Masaomi Nangaku · Yasushi Sakata \\ Kazuyo Sasaki (D) - Kazumi Mori-Anai (D) - Tomohisa Iwasaki • \\ Koume Hamada
}

Received: August 27, 2021 / Accepted: November 2, 2021 / Published online: December 2, 2021

(C) The Author(s) 2021

\section{ABSTRACT}

Introduction: This long-term post-marketing surveillance (SAPPHIRE) collected information on the safety and effectiveness of canagliflozin

Supplementary Information The online version contains supplementary material available at https:// doi.org/10.1007/s12325-021-01984-4.

SAPPHIRE: A large Scale, Prospective Post-marketing surveillance of sodium glucose co-transporter 2 inhibitor, canagllflozin, for the treatment of type 2 diabetes mellitus.

\section{N. Inagaki}

Department of Diabetes, Endocrinology and Nutrition, Kyoto University Graduate School of

Medicine, Kyoto, Japan

e-mail: inagaki@kuhp.kyoto-u.ac.jp

M. Nangaku

Division of Nephrology and Endocrinology, The

University of Tokyo Graduate School of Medicine,

Tokyo, Japan

e-mail: mnangaku-tky@umin.ac.jp

\section{Y. Sakata}

Department of Cardiovascular Medicine, Osaka University Graduate School of Medicine, Osaka, Japan

e-mail: yasushisk@cardiology.med.osaka-u.ac.jp

K. Sasaki $(\square)$

Ikuyaku. Integrated Value Development Division, Mitsubishi Tanabe Pharma Corporation, 3-2-10, Dosho-machi, Chuo-ku, Osaka 541-8505, Japan e-mail: sasaki.kazuyo@mh.mt-pharma.co.jp (approved dose $100 \mathrm{mg}$ ) prescribed to patients with type 2 diabetes mellitus (T2DM) in realworld practice in Japan.

Methods: Patients with T2DM who were prescribed canagliflozin between December 2014 and September 2016 were registered and observed for up to 3 years. Safety was evaluated in terms of adverse drug reactions (ADRs). Effectiveness was assessed in terms of glycaemic control. Data were also analysed across age subgroups $(<65, \geq 65$ to $<75$, and $\geq 75$ years old) and the estimated glomerular filtration rate

\author{
K. Mori-Anai · T. Iwasaki \\ Ikuyaku. Integrated Value Development Division, \\ Mitsubishi Tanabe Pharma Corporation, Tokyo, \\ JapanK. Mori-Anai \\ e-mail: mori.kazumi@ma.mt-pharma.co.jp \\ T. Iwasaki \\ e-mail: iwasaki.tomohisa@mr.mt- \\ pharma.co.jp \\ K. Hamada \\ Quality and Vigilance Division, Mitsubishi Tanabe \\ Pharma Corporation, Osaka, Japan \\ e-mail: hamada.koume@ma.mt-pharma.co.jp
}


(eGFR) categories for chronic kidney disease (G1-G5 based on eGFR) at baseline.

Results: A total of 12,227 patients were included in the safety analyses and 11,675 in effectiveness analyses. Overall, 7104 patients were treated with canagliflozin for $\geq 3$ years. The mean age, haemoglobin A1c (HbA1c), and eGFR at baseline were $58.4 \pm 12.5$ years, $8.01 \pm 1.49 \%$, and $80.04 \pm 21.85 \mathrm{~mL} / \mathrm{min} /$ $1.73 \mathrm{~m}^{2}$, respectively. There were 1836 ADRs in 1312 patients (10.73\%) and 268 serious ADRs in 225 patients $(1.84 \%)$. The most common ADRs were those related to volume depletion (1.39\%), genital infection (1.34\%), polyuria/pollakiuria $(1.23 \%)$, and urinary tract infection $(1.19 \%)$. The frequencies of ADRs tended to increase with age and stage of chronic kidney disease. The reductions in mean $\mathrm{HbA} 1 \mathrm{c}$ after starting canagliflozin were maintained for up to 3 years with a mean change of $-0.68 \%(n=6345$ at 3 years). Maintained reductions in mean $\mathrm{HbA1c}$ were observed in each age subgroup and in patients with G1-G3b renal function.

Conclusion: This surveillance in real-world clinical practice showed that canagliflozin provides sustained glucose-lowering effects in patients with T2DM, including elderly patients and patients with moderate renal impairment, without new safety concerns beyond those already described in the Japanese package insert.

Trial Registration: JapicCTI-153048.

\section{PLAIN LANGUAGE SUMMARY}

Canagliflozin is a sodium-glucose cotransporter 2 (SGLT2) inhibitor that lowers blood glucose levels by increasing urinary glucose excretion. It was approved for the management of blood glucose levels in patients with type 2 diabetes mellitus following clinical trials. However, clinical trials may not fully represent the safety or effectiveness of a drug in real-world clinical practice. Therefore, a 3-year post-marketing surveillance was performed in Japan to obtain safety and effectiveness data for a large group of 12,227 patients with type 2 diabetes mellitus and various demographic/clinical characteristics. Safety and effectiveness data were collected for up to 3 years while patients were treated with canagliflozin. Adverse drug reactions occurred in $10.73 \%$ of patients. The most common types of adverse drug reactions were those related to volume depletion (body fluid decreased), followed by genital infection, polyuria/pollakiuria (increased urination), and urinary tract infection. Adverse drug reactions tended to be more common in elderly patients and in patients with renal impairment. As expected, canagliflozin was associated with improvements in haemoglobin A1c, a marker of blood glucose control, in patients with type 2 diabetes, including in elderly patients and patients with moderate renal impairment. In this surveillance in real-world clinical practice, long-term treatment with canagliflozin raised no new safety concerns beyond the information already included in the Japanese package insert. Canagliflozin provides sustained glucose-lowering effects.

Keywords: Canagliflozin; Japan; Postmarketing surveillance; Real-world; Safety; Sodium-glucose cotransporter 2 inhibitor; Type 2 diabetes mellitus 


\section{Key Summary Points}

Why carry out this study?

The SAPPHIRE surveillance registered over 12,000 patients with type 2 diabetes mellitus (T2DM) who started treatment with canagliflozin for the first time to provide insight into the safety and effectiveness of canagliflozin in real-world clinical practice in Japan. This included elderly patients and patients with impaired renal function.

\section{What was learned from this study?}

The safety profile of canagliflozin was consistent with that already described in the Japanese package insert, and no additional concerns were identified from this surveillance.

There was a continuous improvement in glycaemic control that was maintained for up to 3 years among patients treated with canagliflozin.

Continuous reductions in mean haemoglobin A1c were also observed in each age group and in patients with G1-G3b renal function (estimated glomerular filtration rate $\geq 30 \mathrm{~mL} / \mathrm{min} /$ $1.73 \mathrm{~m}^{2}$ ).

This surveillance in real-world clinical practice showed that canagliflozin provides sustained glucose-lowering effects in patients with T2DM, including elderly patients and patients with moderate renal impairment, without new safety concerns beyond those already described in the Japanese package insert.

\section{INTRODUCTION}

Canagliflozin is a sodium-glucose cotransporter 2 (SGLT2) inhibitor that is approved in many countries owing to its benefits on lowering blood glucose levels and its safety profile in patients with type 2 diabetes mellitus (T2DM). In Japan, canagliflozin has been available since 2014 at an approved dose of $100 \mathrm{mg}$ [1] following its clinical trial program, which confirmed its efficacy and safety in patients with T2DM [2]. While comprehensive, the clinical trials in Japan enrolled a small number of patients relative to the global trials and the duration of treatment was up to 1 year. Furthermore, the eligibility criteria of clinical trials were restrictive in terms of the patients' age, renal function, and other clinically relevant characteristics. Thus, larger and longer studies are needed in Japanese patients across a broader population that more closely reflects the realworld setting.

To provide further insight into the safety and effectiveness of canagliflozin in a larger group of patients in the real-world setting, SAPPHIRE (A large ScAle, Prospective Post-marketing surveillance of sodium glucose co-transporter 2 inHibitor, canaglIflozin, for the tREatment of type 2 diabetes mellitus) was established in Japan. This surveillance was conducted over a long-term observation period (3 years) in real-world clinical practice. The SAPPHIRE surveillance intended to register over 10,000 patients with T2DM who started treatment with canagliflozin for the first time between December 2014 and September 2016. Interim data from this surveillance were published at 1 and 2 years [3-5]. Here, we report the safety and effectiveness of canagliflozin with up to 3 years of follow-up in SAPPHIRE.

In Japan, the recommendations on the proper use of SGLT2 inhibitors state that SGLT2 inhibitors should be used with caution when prescribed to elderly patients aged 75 years or more, or to patients aged 65-74 years with geriatric syndrome [6, 7]. A surveillance of canagliflozin in elderly patients in clinical practice in Japan was conducted to evaluate its safety and effectiveness for up to 1 year of treatment [8]. However, that surveillance had a small sample size and a limited observation period of 1 year. Therefore, the safety and effectiveness of canagliflozin in elderly patients with T2DM were evaluated using data from SAPPHIRE. Furthermore, while the safety and 
effectiveness of canagliflozin in patients with renal impairment have been evaluated in global clinical trials [9], the Japanese clinical trials enrolled very few or no patients with eGFR $<60 \mathrm{~mL} / \mathrm{min} / 1.73 \mathrm{~m}^{2}$ [10-15], and information regarding the safety and effectiveness in patients with renal impairment was not sufficient. Therefore, sub-analyses of SAPPHIRE were performed to evaluate the safety and effectiveness of canagliflozin according to the stage of chronic kidney disease.

\section{METHODS}

\section{Ethics}

SAPPHIRE was approved by the Ministry of Health, Labour and Welfare of Japan, and was conducted by Mitsubishi Tanabe Pharma Corporation in collaboration with Daiichi Sankyo Co., Ltd. in compliance with Good Post-marketing Study Practice in Japan. All data were collected anonymously by clinicians using case report forms for patients treated in real-world clinical practice. Japanese Good Post-marketing Study Practice does not require the collection of informed consent from patients or ethical approval from the participating institutions. This surveillance was registered under the accession number JapicCTI-153048 (https:// rctportal.niph.go.jp/s/detail/jp?trial_id= JapicCTI-153048).

\section{Patients and Treatments}

Patients with T2DM who were prescribed canagliflozin for the first time between December 2014 and September 2016 at 1524 participating facilities across 47 prefectures were to be registered within 14 days by their clinicians, who used electronic case report forms to upload data to the central database. Canagliflozin was to be prescribed once daily in accordance with the Japanese package insert [1], either as monotherapy or in combination with other antihyperglycaemic drugs. The dose(s) and type(s) of concomitant antihyperglycaemic drugs could be adjusted in accordance with their approved labels. All treatment decisions, including lifestyle modifications, were at the physician's discretion.

\section{Data Collection}

The clinicians completed electronic case report forms to collect data on their patients at baseline, 3 months, 6 months, 1 year, 2 years, and 3 years, or at discontinuation. Baseline data included the patient's sex, age, duration of T2DM, body weight, body mass index (BMI), estimated glomerular filtration rate (eGFR), haemoglobin A1c (HbA1c), fasting plasma glucose, presence/absence of diabetic complications or comorbidities, and administration of canagliflozin and concomitant drugs. Renal function was classified on the basis of eGFR categories for chronic kidney disease at baseline (in $\mathrm{mL} / \mathrm{min} / 1.73 \mathrm{~m}^{2}$ ) as G1 ( $\geq 90$ ), G2 ( $\geq 60$ to $<90)$, G3a $(\geq 45$ to $<60)$, G3b $(\geq 30$ to $<45)$, G4 $(\geq 15$ to $<30)$, and G5 $(<15)$ [16]. eGFR was calculated using the serum creatinine value, and adjusted for age and sex [17]. At each follow-up, clinicians recorded data on adverse events (AEs) and laboratory test data, together with information on the administration of canagliflozin, including the duration of treatment, reasons for stopping treatment, and previous/concomitant treatments. AEs were identified by the physicians on the basis of the patient's reports, medical records, interviews, and laboratory test data.

Safety was evaluated in terms of adverse drug reactions (ADRs), including abnormal laboratory test data. ADRs were defined as AEs for which a causal relationship with canagliflozin could not be ruled out, i.e. related or unknown. The following categories of ADRs were denoted as ADRs of special interest: hypoglycaemia-related ADRs, genital infections, urinary tract infections, ADRs associated with polyuria/pollakiuria, ADRs associated with volume depletion (thrombosis/embolism, including dehydration and cerebral infarction), ADRs associated with ketone body increased, renal disorders, hepatic disorders, gastrointestinal disorders, skin and subcutaneous tissue disorders, effects on bone metabolism, and ADRs 
associated with body weight decreased. AEs and ADRs associated with lower limb amputation, cardiovascular events (e.g. ischemic heart disease, cerebrovascular disorders including cerebral infarction, peripheral arterial disease, and cardiovascular death), and malignant tumours were also considered of special interest. Cardiovascular events were identified using Standardised Medical Dictionary for Regulatory Activities Queries, with wide (ischemic heart disease, central nervous system haemorrhage and cerebrovascular conditions) and narrow (cardiac failure) searches. All AEs and ADRs were categorised using Medical Dictionary for Regulatory Activities /Japanese edition, version 23.0. Effectiveness was assessed in terms of changes in HbA1c and fasting blood glucose levels.

\section{Data Analyses}

For this report, we extracted data from the database locked in July 2020. Safety data were analysed using the safety analysis set, which comprised all patients for whom case report forms were collected. Patients were excluded from the safety analysis set in the event of breach of contract, breach of registration, overlapping/duplicate cases, AE not evaluated, or treatment with canagliflozin was not confirmed. Effectiveness data were evaluated using the effectiveness analysis set, which comprised all patients in the safety analysis set who received canagliflozin for the treatment of T2DM and for whom effectiveness data were available. Patients were excluded if they received canagliflozin for an off-label purpose or effectiveness was not evaluated. Data were analysed descriptively in terms of the number and percentage of patients for categorical variables or as the mean \pm standard deviation for continuous variables. Changes in continuous variables from baseline to specific time points were calculated for patients followed up at the indicated time point. For the changes in continuous variables from baseline to 3 years, the last observation carried forward (LOCF) method was also used to impute missing data. For ADRs of special interest, we calculated and evaluated their incidence according to baseline characteristics; the incidence rate ratios were calculated among categories with 95\% confidence intervals to consider the effects of baseline characteristic (sex, age, duration of T2DM, eGFR, and other potential risk factors). Changes in laboratory test data, blood pressure, and body weight over time were compared using paired $t$ tests. SAS version 9.4 (TS1M2; SAS Institute, Cary, NC, USA) was used for all analyses.

\section{RESULTS}

\section{Patients}

Overall, 12,605 patients were registered in the database, of which 12,227 patients were included in the safety analysis set and 11,675 in the effectiveness analysis set (Fig. 1). The mean duration of exposure to canagliflozin was $804.6 \pm 396.6$ days, and 7104 patients were treated for $\geq 3$ years. 5142 patients had discontinued, including 2459 patients who discontinued canagliflozin, 1321 patients who stopped clinical visits, 776 patients who discontinued the observation for another reason, and 586 for whom the reason for discontinuation was not reported. Canagliflozin was discontinued during the surveillance because of the patient's preference (726 patients), AEs (628 patients), no change or exacerbation of diabetes (377 patients), recovery/remission (233 patients), canagliflozin dose change (22 patients), or another reason (666 patients); some patients discontinued because of multiple reasons.

The baseline characteristics are presented in Table 1. Among 12,227 patients included in the safety analysis set, $62.1 \%$ were male and $37.9 \%$ female. The mean age was 58.4 years, $25.6 \%$ of patients were $\geq 65$ to $<75$ years old, and $9.1 \%$ were $\geq 75$ years old. The mean BMI and eGFR were $28.24 \mathrm{~kg} / \mathrm{m}^{2}$ and $80.04 \mathrm{~mL} / \mathrm{min} / 1.73 \mathrm{~m}^{2}$, respectively. The stages of chronic kidney disease were G1 in $22.7 \%$, G2 in $44.6 \%$, G3a in $9.7 \%$, G3b in $2.5 \%$, G4 in $0.4 \%$, G5 in $0.0 \%$, and unknown in $20.0 \%$. Diabetic complications were recorded for $30.2 \%$ of patients, with neuropathy in $11.9 \%$, nephropathy in $20.6 \%$, and retinopathy in $11.9 \%$. Comorbidities included 


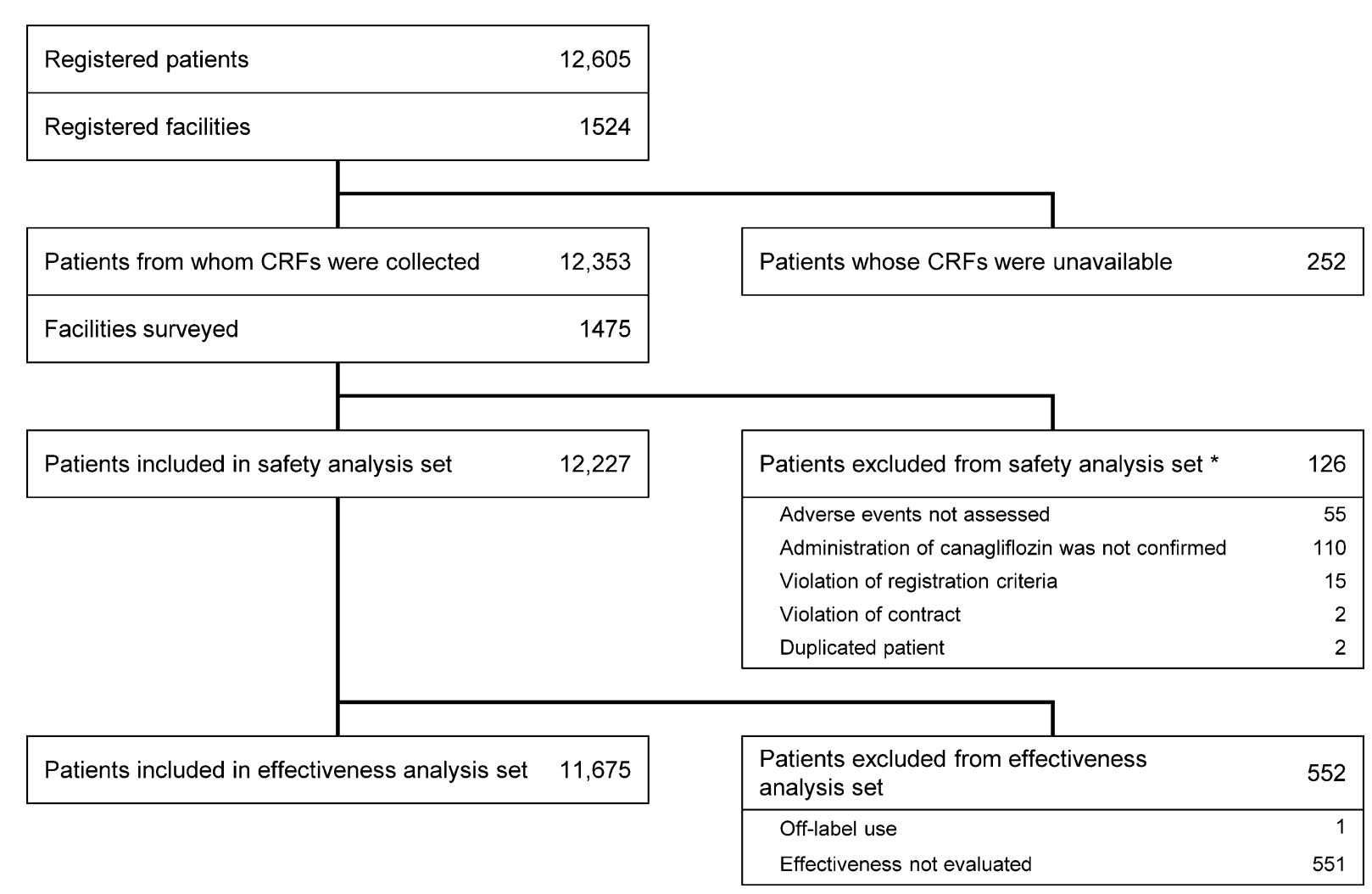

Fig. 1 Patient disposition. * Multiple reasons may apply. $C R F$ case report form

hypertension in $61.3 \%$ and dyslipidaemia in $70.3 \%$ of patients.

Concomitant antidiabetic therapies are summarised in Table S1 in the supplementary material. Overall, $69.6 \%$ of patients were using any class at baseline, $73.8 \%$ at 3 years, and $75.0 \%$ during the observation period. Dipeptidyl peptidase 4 inhibitors were the most frequently prescribed concomitant drugs throughout the surveillance, being prescribed to approximately $50 \%$ of patients at baseline, 1, 2, and 3 years (Table $S 1$ in the supplementary material). The use of biguanides and glucagonlike peptide 1 receptor agonists increased slightly over time from baseline. Glimepiride, gliclazide, and glibenclamide were prescribed to 2484,239 , and 129 patients, respectively. Of these, 2138 (86.1\%), 197 (82.4\%), and 22 (17.1\%) were considered to be compliant with the recommended doses in Japanese patients using SGLT2 inhibitors [6, 7] of $\leq 2 \mathrm{mg} /$ day, $\leq 40 \mathrm{mg} /$ day, and $\leq 1.25 \mathrm{mg} /$ day, respectively. Other concomitant therapies included antihypertensive agents, antidyslipidaemic agents, and diuretics, which were prescribed to $52.4 \%, 48.8 \%$, and $8.0 \%$ of patients, respectively.

\section{Safety}

\section{Adverse Drug Reactions}

Among 12,227 patients in the safety analysis set, 1836 ADRs were reported in 1312 patients (10.73\%) and 268 serious ADRs were reported in 225 patients $(1.84 \%)$ (Table 2). ADRs that occurred in $\geq 0.1 \%$ of patients and serious ADRs in $\geq 0.03 \%$ are listed in Table S2 in the supplementary material. The most common ADRs were pollakiuria $(0.79 \%)$, followed by cystitis $(0.52 \%)$, pruritus genital $(0.48 \%)$, and urinary tract infection $(0.47 \%)$. The most common serious ADR was cerebral infarction $(0.17 \%)$.

The frequencies of ADRs and AEs of special interest are illustrated in Fig. 2 and are listed by the preferred term in Table S3 in the 
Table 1 Patient characteristics $(n=12,227)$

\begin{tabular}{l} 
Characteristic \\
\hline Sex \\
Male \\
Female \\
Age, years \\
Mean $\pm S D$ \\
$<65$ \\
$\geq 65$ to $<75$ \\
$\geq 75$
\end{tabular}

\section{Value}

Body weight, kg

Mean \pm SD

BMI, $\mathrm{kg} / \mathrm{m}^{2}$

$$
\begin{aligned}
& \text { Mean } \pm \text { SD } \\
& <25.0 \\
& \geq 25.0
\end{aligned}
$$

$58.4 \pm 12.5(12,227)$

$7982(65.3 \%)$

$3128(25.6 \%)$

$1117(9.1 \%)$

Duration of diabetes, years

$$
\text { Mean } \pm \mathrm{SD}
$$$$
7.88 \pm 7.08(9590)
$$

HbAlc, \%

$$
\text { Mean } \pm \text { SD }
$$$$
8.01 \pm 1.49(11,694)
$$

Diet therapy ${ }^{a}$

$$
\begin{aligned}
& \text { Prescribed } \\
& \text { Complied }
\end{aligned}
$$$$
5732(46.9 \%)
$$$$
2340(21.6 \%)
$$

Exercise therapy ${ }^{\mathrm{a}}$

$$
\begin{aligned}
& \text { Prescribed } \\
& \text { Complied } \\
& \text { eGFR, } \mathrm{mL} / \mathrm{min} / 1.73 \mathrm{~m}^{2} \\
& \text { Mean } \pm \mathrm{SD} \\
& \text { G1 }(\geq 90) \\
& \text { G2 }(\geq 60 \text { to }<90) \\
& \text { G3a }(\geq 45 \text { to }<60) \\
& \text { G3b }(\geq 30 \text { to }<45) \\
& \text { G4 }(\geq 15 \text { to }<30) \\
& \text { G5 }(<15) \\
& \text { Unknown }
\end{aligned}
$$

\begin{tabular}{|c|c|}
\hline Characteristic & Value \\
\hline \multicolumn{2}{|l|}{ ALT, IU/L } \\
\hline Mean \pm SD & $37.0 \pm 30.5(9218)$ \\
\hline$\geq 31$ & $4044(33.1 \%)$ \\
\hline \multicolumn{2}{|l|}{ Medical history $^{\mathrm{a}}$} \\
\hline $\begin{array}{l}\text { Cardiac/cerebrovascular } \\
\text { disease }\end{array}$ & $649(5.3 \%)$ \\
\hline Heart failure & $62(0.5 \%)$ \\
\hline \multicolumn{2}{|l|}{ Diabetic complications $^{\mathrm{a}}$} \\
\hline Any & $3691(30.2 \%)$ \\
\hline Neuropathy & $1455(11.9 \%)$ \\
\hline Nephropathy & $2513(20.6 \%)$ \\
\hline Retinopathy & $1452(11.9 \%)$ \\
\hline \multicolumn{2}{|l|}{ Comorbidities $^{\mathrm{a}}$} \\
\hline Liver impairment & $3859(31.6 \%)$ \\
\hline Hypertension & $7500(61.3 \%)$ \\
\hline Dyslipidaemia & $8595(70.3 \%)$ \\
\hline
\end{tabular}$$
80.04 \pm 21.85 \text { (9785) }
$$$$
2781(22.7 \%)
$$$$
5448(44.6 \%)
$$$$
1190(9.7 \%)
$$$$
306 \text { (2.5\%) }
$$$$
54(0.4 \%)
$$$$
6(0.0 \%)
$$

$2442(20.0 \%)$
Table 1 continued

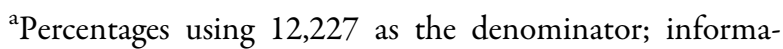
tion was unknown for some patients

Values are $n(\%)$ or mean $\pm \mathrm{SD}$ (available $n$ )

$S D$ standard deviation, BMI body mass index, eGFR estimated glomerular filtration rate, $G 1 \mathrm{eGFR} \geq 90 \mathrm{~mL} / \mathrm{min} /$ $1.73 \mathrm{~m}^{2}, G 2$ eGFR $\geq 60$ to $<90 \mathrm{~mL} / \mathrm{min} / 1.73 \mathrm{~m}^{2}, G 3 a$ $\mathrm{eGFR} \geq 45$ to $<60 \mathrm{~mL} / \mathrm{min} / 1.73 \mathrm{~m}^{2}, G 3 b \mathrm{eGFR} \geq 30$ to $<45 \mathrm{~mL} / \mathrm{min} / 1.73 \mathrm{~m}^{2}, G 4 \mathrm{eGFR} \geq 15$ to $<30 \mathrm{~mL} /$ $\mathrm{min} / 1.73 \mathrm{~m}^{2}, \quad G 5 \mathrm{eGFR}<15 \mathrm{~mL} / \mathrm{min} / 1.73 \mathrm{~m}^{2}, \quad A L T$ alanine aminotransferase

supplementary material. The outcomes of ADRs of special interest are presented in Table S4 in the supplementary material. ADRs associated with volume depletion were the most frequent type, followed by genital infections and ADRs associated with polyuria/pollakiuria. Serious ADRs associated with volume depletion were observed in $0.47 \%$ of patients, with the most common being cerebral infarction, which occurred in 21 patients $(0.17 \%)$. The outcomes of ADRs associated with volume depletion were 
Table 2 Overall incidence of adverse drug reactions (all and serious)

\begin{tabular}{lll}
\hline Group & All ADRs & $\begin{array}{l}\text { Serious } \\
\text { ADRs }\end{array}$ \\
\hline $\begin{array}{c}\text { All patients } \\
\quad(n=12,227)\end{array}$ & $1312(10.73 \%)$ & $225(1.84 \%)$ \\
By age, years & & \\
$<65(n=7982)$ & $766(9.60 \%)$ & $106(1.33 \%)$ \\
$\geq 65$ to $<75$ & $385(12.31 \%)$ & $73(2.33 \%)$ \\
$(n=3128)$ & & \\
$\geq 75(n=1117)$ & $161(14.41 \%)$ & $46(4.12 \%)$
\end{tabular}

By renal function

\begin{tabular}{lrl} 
G1 $(n=2781)$ & $277(9.96 \%)$ & $28(1.01 \%)$ \\
G2 $(n=5448)$ & $616(11.31 \%)$ & $97(1.78 \%)$ \\
G3a $(n=1190)$ & $165(13.87 \%)$ & $41(3.45 \%)$ \\
G3b $(n=306)$ & $55(17.97 \%)$ & $16(5.23 \%)$ \\
G4 $(n=54)$ & $14(25.93 \%)$ & $8(14.81 \%)$ \\
G5 $(n=6)$ & $1(16.67 \%)$ & $0(0 \%)$ \\
\hline
\end{tabular}

Values are $n(\%)$

$A D R$ adverse drug reaction, $e G F R$ estimated glomerular filtration rate, $G 1$ eGFR $\geq 90 \mathrm{~mL} / \mathrm{min} / 1.73 \mathrm{~m}^{2}, \quad G 2$ eGFR $\geq 60$ to $<90 \mathrm{~mL} / \mathrm{min} / 1.73 \mathrm{~m}^{2}, G 3 a$ eGFR $\geq 45$ to $<60 \mathrm{~mL} / \mathrm{min} / 1.73 \mathrm{~m}^{2}, G 3 b$ eGFR $\geq 30$ to $<45 \mathrm{~mL} /$ $\mathrm{min} / 1.73 \mathrm{~m}^{2}, G 4$ eGFR $\geq 15$ to $<30 \mathrm{~mL} / \mathrm{min} / 1.73 \mathrm{~m}^{2}$, G5 eGFR $<15 \mathrm{~mL} / \mathrm{min} / 1.73 \mathrm{~m}^{2}$

recorded as resolved or resolving for 161 ADRs, but 14 ADRs were associated with sequelae, eight were not resolved, and three were fatal. Hypoglycaemia-related ADRs were reported in $34(0.28 \%)$ patients, of whom six $(0.05 \%)$ experienced serious hypoglycaemia-related ADRs. Of these six patients, four were using concomitant sulfonylurea or insulin. There were no episodes of serious hypoglycaemia in patients who received canagliflozin alone. ADRs associated with genital infection were reported in $164(1.34 \%)$ patients. All of these ADRs were non-serious, and the recorded outcome was resolved or resolving for 168 of 172 ADRs. ADRs associated with urinary tract infection were observed in 145 (1.19\%) patients; $12(0.10 \%)$ patients experienced serious ADRs, including urinary tract infection in four patients, pyelonephritis in four patients, pyelonephritis acute in three patients, and prostatitis in one patient. ADRs associated with polyuria/pollakiuria were all non-serious, except for one ADR (thirst). These ADRs frequently occurred within a few weeks after starting canagliflozin (Table S5 in the supplementary material). ADRs associated with ketone body increased were reported in $68(0.56 \%)$ patients, of which six reported ketoacidosis. Of $104(0.85 \%)$ patients who reported ADRs associated with renal disorders, four patients experienced acute kidney injury. ADRs associated with hepatic disorders and gastrointestinal disorders were observed in $0.62 \%$ and $0.86 \%$ of patients, respectively. ADRs associated with skin and subcutaneous tissue disorders occurred in $106(0.87 \%)$ patients. ADRs associated with effects on bone metabolism were reported in $10(0.08 \%)$ patients, including bone fracture in seven patients. ADRs associated with body weight decreased were observed in $16(0.13 \%)$ patients, including one patient with a BMI of $<18.5 \mathrm{~kg} / \mathrm{m}^{2}$.

Events associated with lower limb amputation were reported as AEs and ADRs in five $(0.04 \%)$ and four (0.03\%) patients (Fig. 2, Table S3 in the supplementary material), with incidence rates of 0.02 and 0.01 per 100 personyears, respectively. Cardiovascular events were reported as AEs and ADRs in 123 (1.01\%) and 77 $(0.63 \%)$ patients (Fig. 2, Table S3 in the supplementary material), with incidence rates of 0.45 and 0.28 per 100 person-years, respectively. The incidence rates of cardiovascular AEs and ADRs were higher in patients with a history of cardiovascular/cerebrovascular disease than in patients without a history of these diseases (1.65 vs 0.36 per 100 person-years for cardiovascular AEs and 1.29 vs 0.20 per 100 person-years for cardiovascular ADRs, respectively). Cerebral infarction was reported as AEs and ADRs in 43 $(0.35 \%)$ and $36(0.29 \%)$ patients (Table S3 in the supplementary material), with incidence rates of 0.16 and 0.13 per 100 person-years, respectively. Myocardial infarction was reported as AEs and ADRs in $19(0.16 \%)$ and 13 (0.11\%) patients (Table $\mathrm{S} 3$ in the supplementary material), with incidence rates of 0.07 and 0.05 per 


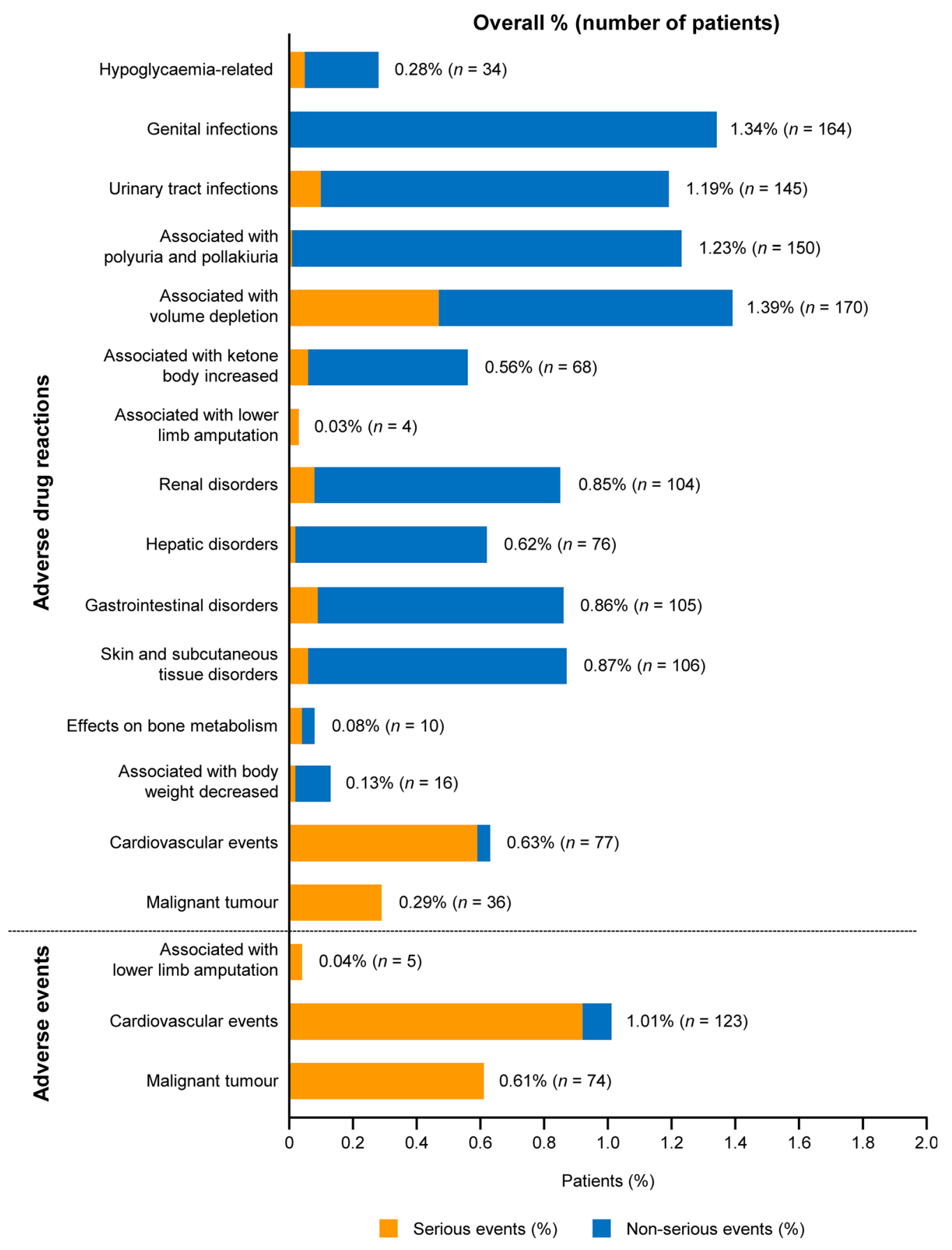

Fig. 2 Adverse drug reactions/adverse events of special interest $(n=12,227)$

100 person-years, respectively. Malignant tumours were reported as AEs and ADRs in 74 $(0.61 \%)$ and $36(0.29 \%)$ patients (Fig. 2, Table S3 in the supplementary material), with incidence rates of 0.27 and 0.13 per 100 person-years, respectively.
Other ADRs that occurred in $\geq 0.1 \%$, but were excluded from the categories of ADRs of special interest, included dyslipidaemia $(0.18 \%)$, dizziness $(0.16 \%)$, malaise $(0.13 \%)$, atrial fibrillation (0.10\%), and blood 
triglycerides increased $(0.10 \%)$ (Table $\mathrm{S} 2$ in the supplementary material).

The incidences of ADRs of special interest in $\geq 1 \%$ of patients according to patient characteristics are presented in Fig. S1 in the supplementary material. For genital infections, the incidence rate ratio was $\geq 2$ and the lower 95\% CI was $\geq 1.0$, indicating a higher incidence, in the following subgroups of patients: female; BMI $\geq 30.0$ to $<35.0 \mathrm{~kg} / \mathrm{m}^{2}$ and $\geq 35.0 \mathrm{~kg} / \mathrm{m}^{2}$; and history of urinary tract or genital infection (Fig. S1a in the supplementary material). For urinary tract infection, these subgroups were female; $B M I \geq 35.0 \mathrm{~kg} / \mathrm{m}^{2}$; history of urinary tract or genital infection; and concurrent neuropathy (Fig. S1b in the supplementary material). The incidence of ADRs associated with polyuria/pollakiuria was greater in the following subgroups of patients: age $\geq 75$ years; duration of $\mathrm{T} 2 \mathrm{DM} \geq 5$ to $<10$ years, $\geq 10$ to $<15$ years, or $\geq 15$ years; and concurrent dyslipidaemia (Fig. S1c in the supplementary material). Patients with an eGFR of $\geq 45$ to $<60$ (G3a), $\geq 30$ to $<45$ (G3b), or $\geq 15$ to $<30$ (G4) $\mathrm{mL} / \mathrm{min} / 1.73 \mathrm{~m}^{2}$ had a numerically higher incidence of ADRs associated with polyuria/ pollakiuria than patients with an eGFR of $\geq 90 \mathrm{~mL} / \mathrm{min} / 1.73 \mathrm{~m}^{2}$. The incidence of ADRs associated with volume depletion was increased in the following subgroups: age $\geq 75$ years; duration of $\mathrm{T} 2 \mathrm{DM} \geq 15$ years; eGFR $\geq 45$ to $<60$ (G3a), $\geq 30$ to $<45$ (G3b), or $\geq 15$ to $<30$ (G4) $\mathrm{mL} / \mathrm{min} / 1.73 \mathrm{~m}^{2}$; current/history of cardio/cerebrovascular disease, cardiac failure, nephropathy, retinopathy, or hypertension; and concomitant treatment with an antihypertensive drug. The incidence ratio between patients with or without prescription for diuretics was 1.99 (Fig. S1d in the supplementary material).

The frequencies of ADRs and serious ADRs increased with age and stage of chronic kidney disease, except in G5 patients (Table 2). In particular, ADRs associated with polyuria/pollakiuria, ADRs associated with volume depletion, renal disorders, gastrointestinal disorders, and AEs and ADRs of cardiovascular events were more common in elderly patients (Fig. S2 in the supplementary material). ADRs that were more common in patients with renal impairment were those related to volume depletion, renal disorders, and AEs and ADRs of cardiovascular events (Fig. S3 in the supplementary material). Of six patients with G5, one patient experienced ADRs of renal disorders and gastrointestinal disorders.

\section{Body Weight, Blood Pressure, and Laboratory Test Data}

In the overall cohort, the reductions in mean body weight were continued for up to 3 years (Fig. S4a in the supplementary material). There were reductions in mean body weight over 3 years in subgroups by age (Fig. S4b in the supplementary material) and by eGFR (G1-G3b; Fig. S4c in the supplementary material). At 3 years for patients with follow-up data, the mean eGFR $\left(\mathrm{mL} / \mathrm{min} / 1.73 \mathrm{~m}^{2}\right)$ in the $\mathrm{G} 1, \mathrm{G} 2$, G3a, G3b, and G4 subgroups were $98.71 \pm 19.15 \quad(n=1380), \quad 75.03 \pm 13.12$ $(n=2770), \quad 54.19 \pm 11.12 \quad(n=577)$, $40.51 \pm 9.78 \quad(n=142), \quad$ and $\quad 25.92 \pm 11.22$ $(n=9)$, respectively, with mean changes from baseline of $-6.89,-0.28,0.64,0.51$, and 1.12 , respectively (Fig. 3). The number of patients in the G5 subgroup was too small to evaluate the changes in body weight and eGFR. Within the overall cohort, reductions in mean systolic blood pressure, diastolic blood pressure, triglycerides, low-density lipoprotein cholesterol, and hepatic function parameters were observed at 3 years, whereas the mean haematocrit and high-density lipoprotein cholesterol increased (Table S6 in the supplementary material).

\section{Effectiveness}

In the overall cohort, the mean HbA1c decreased from baseline through to 3 years, with mean changes of $-0.68 \%$ and $-0.67 \%$ at 3 years for patients with follow-up data and at 3 years with LOCF, respectively (Fig. 4a). HbA1c was $<7.0 \%$ in $1673 / 4911$ (34.1\%) patients with follow-up at 3 years and in 2876/8807 (32.7\%) patients at 3 years with LOCF. The maintained reductions in HbA1c were also observed when patients were divided by age (Fig. $4 \mathrm{~b}$ ). The mean HbA1c decreased over 3 years in the G1, G2, 


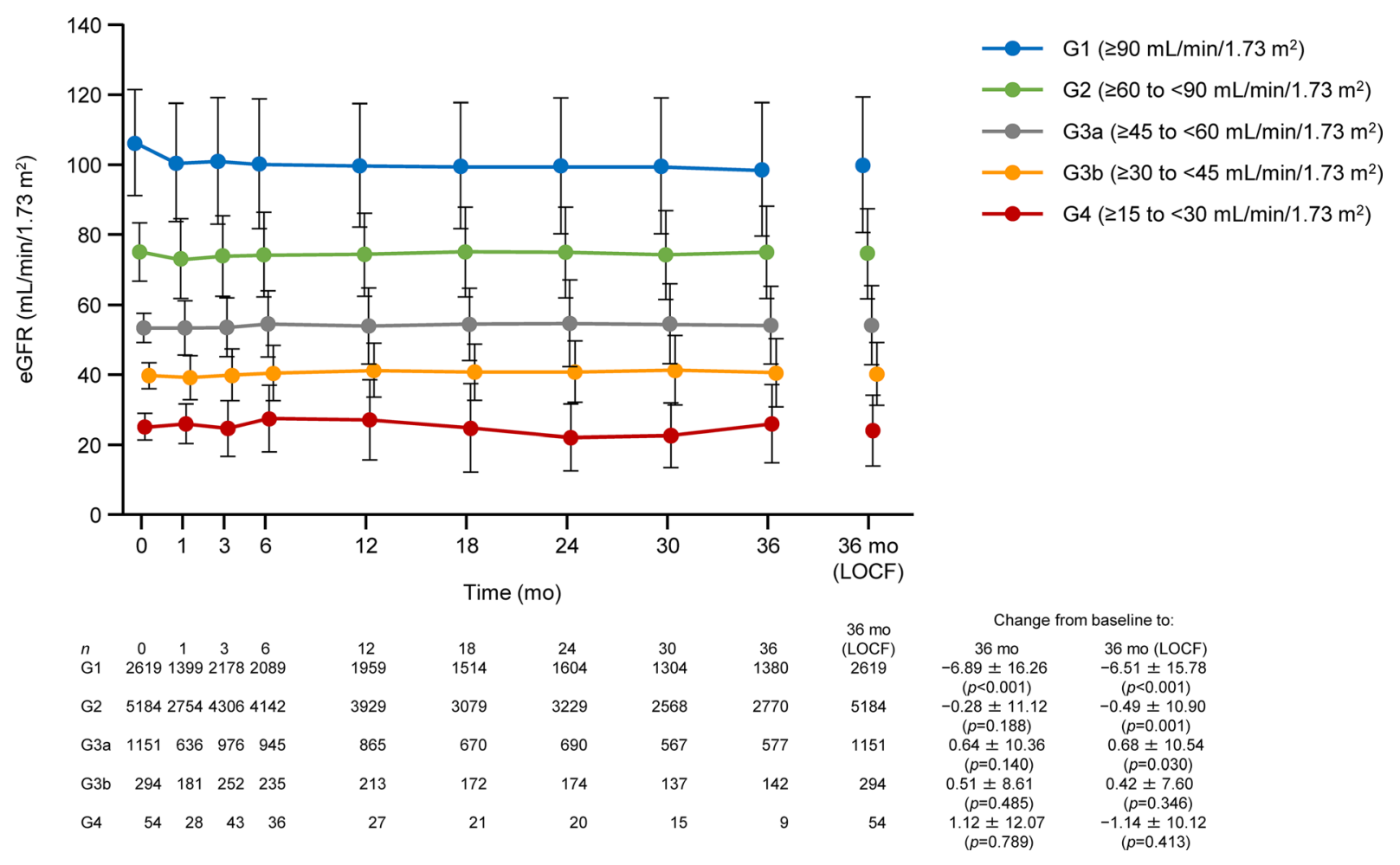

Fig. 3 Changes in eGFR over time in patients divided into subgroups by renal function at baseline. Values are mean \pm standard deviation with $p$ values from paired

G3a, and G3b subgroups; the HbA1c reduction was numerically greatest in the G1 subgroup (Fig. 4c). Mean fasting blood glucose decreased from baseline to 3 years for patients with follow-up data and at 3 years with LOCF (Table S6).

\section{DISCUSSION}

SAPPHIRE, a long-term, large-scale post-marketing surveillance, was conducted to evaluate the safety and effectiveness of canagliflozin in patients with T2DM in clinical practice in Japan. In this surveillance, data from approximately 12,000 patients were analysed. The large number of patients and participating sites support the relevance of these data to clinical practice in Japan. In addition, the surveillance included approximately 4000 elderly patients aged $\geq 65$ years and 1500 patients with an eGFR of $<60 \mathrm{~mL} / \mathrm{min} / 1.73 \mathrm{~m}^{2}$. Thus, this surveillance allowed us to evaluate the safety and $t$ tests. eGFR estimated glomerular filtration rate, $L O C F$ last observation carried forward, mo month

effectiveness of canagliflozin over a longer duration of treatment in a broader range of patients with varying characteristics compared with earlier clinical trials [2, 10-15].

Regarding the safety of canagliflozin, the types of ADRs reported in this surveillance were also recorded in the clinical trial program [2] and were generally similar to those reported for other SGLT2 inhibitors [18-21]. Most of the ADRs with an incidence of $\geq 0.1 \%$ have already been listed in the package insert for canagliflozin [1]. Other ADRs with an incidence of $\geq$ $0.1 \%$ included atrial fibrillation, hepatic function abnormal, dyslipidaemia, and blood triglycerides increased. Although these events were considered to be unknown ADRs, there is currently no reasonable relationship between these events and canagliflozin. Patient background factors, including comorbidities, are likely explanations for these events. On the basis of the above, the safety profile of canagliflozin was considered to be consistent with that 
a Overal

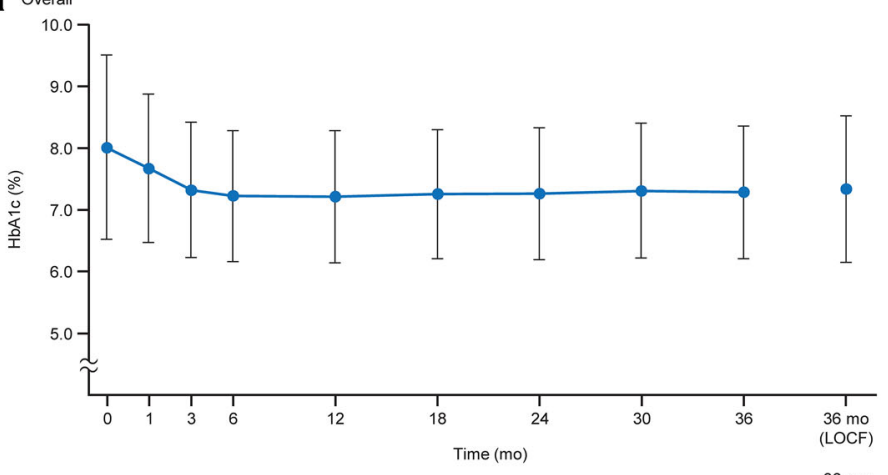

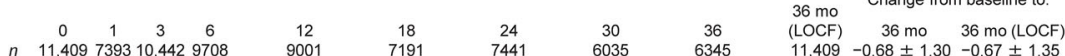
$\begin{array}{lllllll}n-11,409739310,4429708 & 9001 & 7191 & 7441 & 6035 & 6345 & 11,409 \\ -0.68 \pm 1.30 & -0.67 \pm 1.35 \\ (p<0.001) & & & \end{array}$

\section{b}

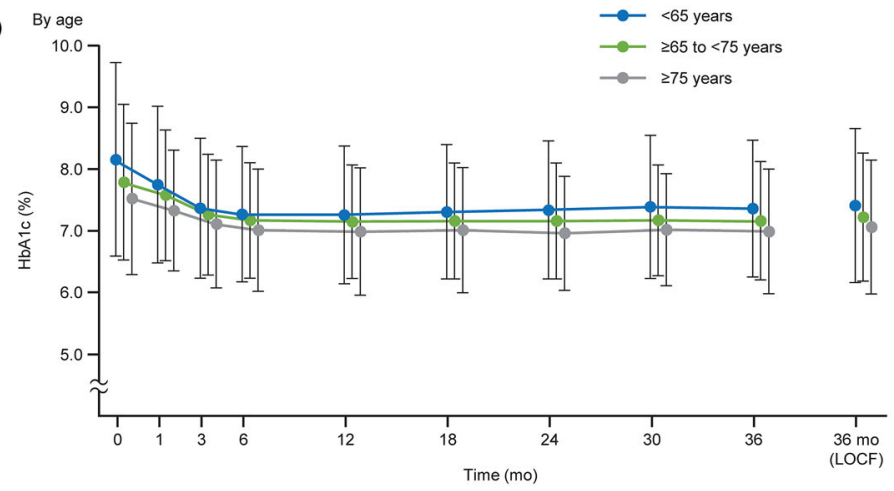

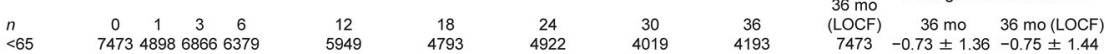
$\geq 65$ to $<752902187026662488 \quad 2296 \quad 1845 \quad 1930 \quad 1570 \quad 1674 \quad 2902 \quad(p<0.001) \quad(p<0.001)$ $\begin{array}{lllll}1930 & 1570 & 1674-290 & -290 & -0.02 \pm 1.19-0.57 \pm 1.18\end{array}$ $\begin{array}{lllllllllllll}275 & 1034 & 625 & 910 & 841 & 756 & 553 & 589 & 446 & 478 & 1034 & -0.48 \pm 1.08 & -0.46 \pm 1.06\end{array}$

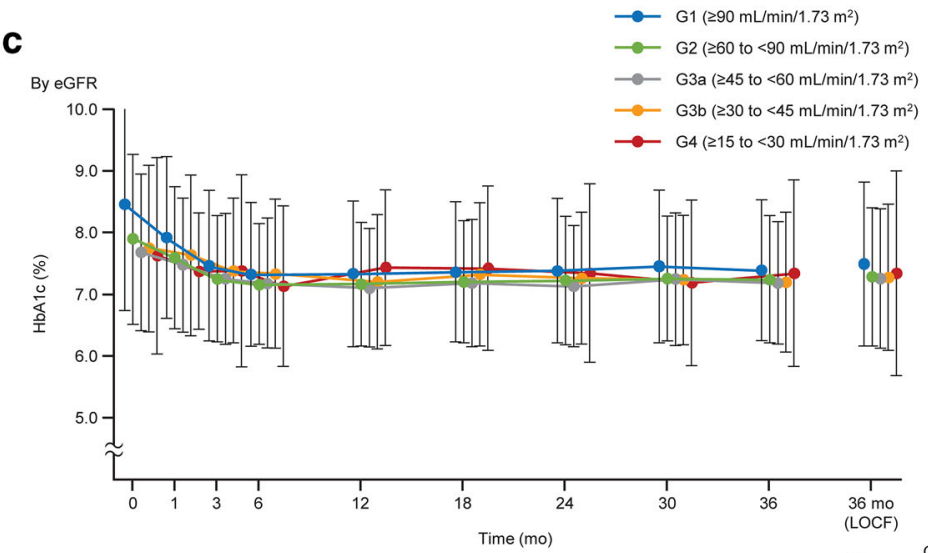

\begin{tabular}{|c|c|c|c|c|c|c|c|c|c|c|c|c|}
\hline & & & & & & & & & & $36 \mathrm{mo}$ & & \\
\hline & & & & 6 & 12 & 18 & 24 & 30 & 36 & (LOCF) & $36 \mathrm{mo}$ & $36 \mathrm{mo}$ (LOCF) \\
\hline G1 & 2657 & 1784 & 2461 & 2281 & 2126 & 1689 & 1748 & 1457 & 1519 & 2657 & $-0.93 \pm 1.41$ & $-0.97 \pm 1.58$ \\
\hline G2 & 5220 & 3393 & 4789 & 4462 & 4145 & 3403 & 3495 & 2848 & 3027 & 5220 & $\begin{array}{c}-0.62 \pm 1.30 \\
(p<0.001)\end{array}$ & $\begin{array}{c}-0.61 \pm 1.28 \\
(p<0.001)\end{array}$ \\
\hline G3a & 1152 & 744 & 1050 & 989 & 901 & 716 & 738 & 612 & 615 & 1152 & $\begin{array}{c}-0.48 \pm 1.11 \\
(p<0.001)\end{array}$ & $\begin{array}{c}-0.42 \pm 1.16 \\
(p<0.001)\end{array}$ \\
\hline G3b & 294 & 200 & 267 & 250 & 224 & 180 & 180 & 148 & 151 & 294 & $\begin{array}{c}-0.57 \pm 1.28 \\
(p<0.001)\end{array}$ & $\begin{array}{c}-0.47 \pm 1.22 \\
(p<0.001)\end{array}$ \\
\hline G4 & 51 & 28 & 45 & 36 & 28 & 23 & 20 & 16 & 10 & 51 & $\begin{array}{c}-0.32 \pm 1.41 \\
(p=0.490)\end{array}$ & $\begin{array}{c}-0.27 \pm 1.00 \\
(p=0.057)\end{array}$ \\
\hline
\end{tabular}


4Fig. 4 Changes in HbAlc over time in the overall cohort (a) and in patients divided into subgroups by age (b) and eGFR (c) at baseline. In c, data are shown for G1-G4. Values are mean \pm standard deviation with $p$ values from paired $t$ tests. $e G F R$ estimated glomerular filtration rate, $L O C F$ last observation carried forward, mo month

already described in the package insert [1] and no additional concerns were identified in this surveillance.

We also investigated the potential associations between patient characteristics and ADRs highlighted in the package insert for canagliflozin [1] and the recommendations on the proper use of SGLT2 inhibitors [6, 7]. The characteristics of patients in whom ADRs of special interest occurred were similar to those described elsewhere [6, 7, 22-25]. Of note, many of the patients with serious hypoglycaemia in the present study were also using insulin or sulfonylurea in combination with canagliflozin. Genital and urinary tract infections were more frequent in female patients, obese patients, and patients with a history of either type of infection. For urinary tract infections, the incidence was also high in patients with diabetic neuropathy. Polyuria/pollakiuria occurred relatively soon after administration of canagliflozin. Advanced age and impaired renal function were detected as patient background factors in common with ADRs polyuria/pollakiuria and volume depletion. In addition, the incidence of volume depletion in patients with a concomitant diuretic was high. The patient with ketoacidosis reported sick days due to infection, or reductions in their insulin doses. On the basis of the above results, when prescribing canagliflozin to patients with such characteristics, physicians should monitor these patients more carefully and use canagliflozin in accordance with the package insert for canagliflozin [1] and the recommendations on the proper use of SGLT2 inhibitors [6, 7].

Regarding lower limb amputation, an increased risk was detected among patients treated with canagliflozin in the CANVAS program [26]. However, the subsequent CREDENCE trial detected no increase in AEs associated with lower limb amputation in patients with T2DM and chronic kidney disease with albuminuria [27]. In SAPPHIRE, lower limb amputation occurred in five $(0.04 \%)$ patients, with an incidence rate of 0.2 per 1000 person-years. The incidence of lower limb amputation was lower in SAPPHIRE than that reported in a Japanese epidemiological survey (0.47 per 1000 personyears) [28]. These results may suggest that canagliflozin does not increase the risk of lower limb amputation in Japanese patients.

Results of the CANVAS program [29-31] revealed that canagliflozin is associated with a reduced risk of cardiovascular events in patients with T2DM and high cardiovascular risk. In SAPPHIRE, cardiovascular events were reported as AEs in $1.01 \%$ of patients, corresponding to an incidence rate of 4.5 per 1000 person-years, with cerebral infarction in $0.35 \%$ (1.6 per 1000 person-years) and myocardial infarction in $0.16 \%$ (0.7 per 1000 person-years). Although direct comparisons should be interpreted carefully because of differences in patient demographics and definitions of cardiovascular events, the incidence of cardiovascular events was lower in SAPPHIRE than in other epidemiological studies of Japanese patients with T2DM [32-35]. For example, in the Japan Diabetes Complications Study [33], of patients with T2DM, the incidences of brain and myocardial infarction were 6.29 and 3.84 per 1000 personyears, respectively. The present results may suggest that the incidence of cardiovascular events was reduced in high-risk patients included in SAPPHIRE.

The safety of canagliflozin in elderly patients and patients with impaired renal function was also investigated using data from the SAPPHIRE surveillance. The incidences of ADRs and serious ADRs, including those with unclear causality, were higher in elderly patients and in patients with impaired renal function. It is known that ADRs are more likely to occur in those patients because of multiple factors, such as comorbidities and need for polypharmacy $[36,37]$. Therefore, when prescribing canagliflozin to these patients, it is important to carefully monitor the patient's condition and consider recommendations for proper use $[1,6,7]$. 
Body weight, blood pressure, and laboratory test data were evaluated. The changes in body weight, blood pressure, hepatic function parameters, and lipids in this surveillance were comparable with those observed in the clinical trials of canagliflozin [10-15]. Canagliflozin was not associated with deteriorations in eGFR in patients with impaired renal function. These results may provide further evidence supporting the pleiotropic effects of SGLT2 inhibitors, including weight loss, blood pressure reduction, hepatic protection, renal protection, and lipid metabolism improvement, albeit with inconsistent effects on low-density lipoprotein cholesterol [38, 39].

The effectiveness evaluation revealed a lowering of HbA1c that was sustained for up to 3 years after the initiation of canagliflozin in the overall population. This improvement was observed in each age group and within the G1-G3b subgroups. The extent of the decrease in mean HbA1c values was smaller in elderly patients and in patients with impaired renal function as compared with the changes in nonelderly patients and patients with normal renal function (G1). The glucose-lowering effect of SGLT2 inhibitors resulting from increased urinary glucose excretion is thought to depend on baseline blood glucose levels and renal function [40]. Therefore, these results might be attributable to baseline blood glucose levels and the degree of renal function.

\section{Limitations}

There are several limitations inherent to this surveillance that warrant mention, especially the absence of a control group, missing data for some variables, and the possibility that some ADRs/serious ADRs were not reported. Furthermore, there were large differences in the numbers of patients between the age and renal function subgroups. In particular, renal function was classified as G4 and G5 in just 54 and six patients, which limits the reliability of the safety and effectiveness assessments in these subgroups. Changes in concomitant treatments may also influence the results of this surveillance. These limitations may affect the overall generalisability of the results and further research and evidence is needed.

\section{CONCLUSIONS}

This surveillance in real-world clinical practice showed that canagliflozin provides sustained glucose-lowering effects in patients with T2DM, including elderly patients and patients with moderate renal impairment, without new safety concerns beyond the information already described in the Japanese package insert.

\section{ACKNOWLEDGEMENTS}

We wish to thank the prescribing physicians, nurses, and other clinical staff at the participating facilities, and all of the patients who were involved in this post-marketing surveillance. We also wish to thank Y. Watanabe (Takumi Information Technology Inc.) and T. Goto (Mitsubishi Tanabe Pharma Corporation) for conducting the analyses, and K. Arakawa, K. Ueta, and A. Takahashi (Mitsubishi Tanabe Pharma Corporation) for insightful discussions.

Funding. This surveillance was funded by Mitsubishi Tanabe Pharma Corporation and Daiichi Sankyo Co., Ltd. Mitsubishi Tanabe Pharma Corporation funded the journal's Rapid Service and Open Access fees.

Medical Writing Assistance. The authors thank Nicholas D. Smith (EMC K.K.) for medical writing support, which was funded by Mitsubishi Tanabe Pharma Corporation.

Authorship. All named authors meet the International Committee of Medical Journal Editors (ICMJE) criteria for authorship of this article, take responsibility for the integrity of the work as a whole, and have given their approval for this version to be published.

Authors' Contributions. Nobuya Inagaki, Masaomi Nangaku, Yasushi Sakata, and Kazumi Mori-Anai contributed to data interpretation. Kazuyo Sasaki conceived the surveillance and 
contributed to data interpretation. Tomohisa Iwasaki contributed to statistical analyses and data interpretation. Koume Hamada conceived and designed the surveillance, and contributed to data interpretation. All authors contributed to manuscript development and approved the final manuscript.

Prior Presentation. Results of the current analysis at 3 years have not been published elsewhere, except at the following congresses: 64th Annual Meeting of the Japan Diabetes Society (2021, May 20-22; Kanazawa, Japan; poster) and the 64th Annual Meeting of the Japanese Society of Nephrology (2021, June 18-20; Yokohama, Japan; poster). Results of the interim analyses were published in Jpn Pharmacol Ther. 2018;46(4):499-519, J New Remed Clin. 2019;68(1):9-37, J New Remed Clin. 2020;69(3):288-329, and at the following congresses: 60th Annual Meeting of the Japan Diabetes Society (2017, May 18-20; Nagoya, Japan; poster); 61st Annual Meeting of the Japan Diabetes Society (2018, May 24-26; Tokyo, Japan; poster, oral); 61st Annual Meeting of the Japanese Society of Nephrology (2018, June 8-10; Niigata, Japan; poster); 5th Liver, Diabetes and Metabolism Forum (2018, July 21; Yonago, Japan; oral); 62nd Annual Meeting of the Japan Diabetes Society (2019, May 23-25; Sendai, Japan; poster, oral); 62nd Annual Meeting of the Japanese Society of Nephrology (2019, June 21-23; Nagoya, Japan; poster); 6th Liver, Diabetes and Metabolism Forum (2019, May 25; Sendai, Japan; oral); 63rd Annual Meeting of the Japan Diabetes Society (2020, October 5-16; Virtual conference, Japan; poster); and 63rd Annual Meeting of the Japanese Society of Nephrology (2020, August 19-20; Yokohama, Japan; poster).

Disclosures. Nobuya Inagaki has received research funds from Terumo Corp., Drawbridge Inc., and Asken Inc.; lecture fees from Kowa Company Ltd., MSD K.K., Astellas Pharma Inc., Novo Nordisk Pharma Ltd., Ono Pharmaceutical Co., Ltd., Nippon Boehringer Ingelheim Co., Ltd., Takeda Pharmaceutical Co., Ltd., Mitsubishi Tanabe Pharma Corporation, Sumitomo Dainippon Pharma Co., Ltd., Sanofi K.K., and
Eli Lilly Japan K.K.; and research grants from Kissei Pharmaceutical Co., Ltd., Sanofi K.K., Daiichi Sankyo Co., Ltd., Mitsubishi Tanabe Pharma Corporation, Takeda Pharmaceutical Co., Ltd., Japan Tobacco Inc., Kyowa Kirin Co., Ltd., Sumitomo Dainippon Pharma Co., Ltd., Astellas Pharma Inc., MSD K.K., Ono Pharmaceutical Co., Ltd., Sanwa Kagaku Kenkyusho Co., Ltd., Nippon Boehringer Ingelheim Co., Ltd., Novo Nordisk Pharma Ltd., Novartis Pharma K.K., and Life Scan Japan K.K.

Masaomi Nangaku has received a research fund from Japan Tobacco Inc.; lecture fees from Mitsubishi Tanabe Pharma Corporation, Kyowa Kirin Co., Ltd., Daiichi Sankyo Co., Ltd., Chugai Pharmaceutical Co., Ltd., Torii Pharmaceutical Co., Ltd., Astellas Pharma Inc., AstraZeneca K.K., GSK K.K., and Japan Tobacco Inc.; fees for writing manuscripts from Kyowa Kirin Co., Ltd.; and research grants from Mitsubishi Tanabe Pharma Corporation, Kyowa Kirin Co., Ltd., Daiichi Sankyo Co., Ltd., Chugai Pharmaceutical Co., Ltd., Takeda Pharmaceutical Co., Ltd., Torii Pharmaceutical Co., Ltd., and Astellas Pharma Inc.

Yasushi Sakata has received lecture fees and research grants from Mitsubishi Tanabe Pharma Corporation and Daiichi Sankyo Co., Ltd.

Kazuyo Sasaki, Kazumi Mori-Anai, Tomohisa Iwasaki, and Koume Hamada are employees of Mitsubishi Tanabe Pharma Corporation.

Compliance with Ethics Guidelines. This post-marketing surveillance was approved by the Ministry of Health, Labour and Welfare of Japan and was managed by Mitsubishi Tanabe Pharma Corporation, with partial delegation to Daiichi Sankyo Co., Ltd. The surveillance was conducted in compliance with Good Post-marketing Study Practice. Anonymous data were collected in real-world clinical practice, with treatments prescribed at the physician's discretion. According to Japanese regulations, it is not necessary to obtain informed consent from patients or ethical approval from the participating institutions. Registration number: JapicCTI-153048 (Japan Pharmaceutical Information Center clinical trials database). 
Data Availability. Data are not publicly available to protect patient confidentiality, but may be obtained from the corresponding author upon reasonable request.

Open Access. This article is licensed under a Creative Commons Attribution-NonCommercial 4.0 International License, which permits any non-commercial use, sharing, adaptation, distribution and reproduction in any medium or format, as long as you give appropriate credit to the original author(s) and the source, provide a link to the Creative Commons licence, and indicate if changes were made. The images or other third party material in this article are included in the article's Creative Commons licence, unless indicated otherwise in a credit line to the material. If material is not included in the article's Creative Commons licence and your intended use is not permitted by statutory regulation or exceeds the permitted use, you will need to obtain permission directly from the copyright holder. To view a copy of this licence, visit http://creativecommons.org/licenses/by$\mathrm{nc} / 4.0 /$.

\section{REFERENCES}

1. Mitsubishi Tanabe Pharma Corporation. [CANAGLU® $100 \mathrm{mg}$ tablets. revised June 2019] https:// medical.mt-pharma.co.jp/di/file/dc/can_a.pdf. Accessed 8 June 2021 (In Japanese).

2. Inagaki N, Harashima SI, Iijima H. Canagliflozin for the treatment of type 2 diabetes: a comparison between Japanese and non-Japanese patients. Expert Opin Pharmacother. 2018;19(8):895-908. https://doi.org/10.1080/14656566.2018.1473378.

3. Inagaki N, Nangaku M, Sakata Y, et al. Safety and efficacy of canagliflozin, a sodium-glucose cotransporter 2 inhibitor, as monotherapy and in combination with antidiabetic agents in patients with type 2 diabetes mellitus - an interim analysis of post-marketing surveillance (SAPPHIRE). Jpn Pharmacol Ther. 2018;46(4):499-519 (In Japanese).

4. Inagaki N, Nangaku M, Sakata Y, et al. Safety and efficacy of canagliflozin, an SGLT2 inhibitor, in patients with type 2 diabetes mellitus - an interim analysis of post-marketing surveillance (SAPPHIRE). J New Remed Clin. 2019;68(1):9-37 (In Japanese).
5. Inagaki N, Nangaku M, Sakata Y, Sasaki K, Nakamura H, Hamada K. Safety and efficacy of canagliflozin, an SGLT2 inhibitor, in patients with type 2 diabetes mellitus - the interim analysis of postmarketing surveillance (SAPPHIRE), third report. J New Remed Clin. 2020;69(3):288-329 (In Japanese).

6. Committee on the Proper Use of SGLT2 Inhibitors. Recommendations on the proper use of SGLT2 inhibitors. J Diabetes Investig. 2020;11(1):257-61. https://doi.org/10.1111/jdi.13160.

7. Committee on the Proper Use of SGLT2 Inhibitors. Recommendations for proper use of SGLT2 inhibitors. Revised December 25, 2020. http://www.fa. kyorin.co.jp/jds/uploads/recommendation_SGLT2. pdf. Accessed January 29, 2021. (In Japanese).

8. Goda M, Yamakura T, Sasaki K, Tajima T, Ueno M. Safety and efficacy of canagliflozin in elderly patients with type 2 diabetes mellitus: a 1-year postmarketing surveillance in Japan. Curr Med Res Opin. 2018;34(2):319-27. https://doi.org/10.1080/ 03007995.2017 .1392293$.

9. Yale JF, Bakris G, Cariou B, et al. Efficacy and safety of canagliflozin over 52 weeks in patients with type 2 diabetes mellitus and chronic kidney disease. Diabetes Obes Metab. 2014;16(10):1016-27. https:// doi.org/10.1111/dom.12348.

10. Inagaki $\mathrm{N}$, Kondo $\mathrm{K}$, Yoshinari $\mathrm{T}$, Maruyama $\mathrm{N}$, Susuta Y, Kuki H. Efficacy and safety of canagliflozin in Japanese patients with type 2 diabetes: a randomized, double-blind, placebo-controlled, 12-week study. Diabetes Obes Metab. 2013;15(12): 1136-45. https://doi.org/10.1111/dom.12149.

11. Inagaki $\mathrm{N}$, Kondo $\mathrm{K}$, Yoshinari $\mathrm{T}$, Takahashi $\mathrm{N}$, Susuta Y, Kuki H. Efficacy and safety of canagliflozin monotherapy in Japanese patients with type 2 diabetes inadequately controlled with diet and exercise: a 24-week, randomized, double-blind, placebo-controlled phase III study. Expert Opin Pharmacother. 2014;15(11):1501-15. https://doi. org/10.1517/14656566.2014.935764.

12. Inagaki $\mathrm{N}$, Kondo $\mathrm{K}$, Yoshinari $\mathrm{T}$, Kuki H. Efficacy and safety of canagliflozin alone or as add-on to other oral antihyperglycemic drugs in Japanese patients with type 2 diabetes: a 52-week open-label study. J Diabetes Investig. 2015;6(2):210-8. https:// doi.org/10.1111/jdi.12266.

13. Inagaki $\mathrm{N}$, Harashima $\mathrm{S}$, Maruyama $\mathrm{N}$, Kawaguchi Y, Goda M, Iijima H. Efficacy and safety of canagliflozin in combination with insulin: a doubleblind, randomized, placebo-controlled study in Japanese patients with type 2 diabetes mellitus. Cardiovasc Diabetol. 2016;15:89. https://doi.org/ 10.1186/s12933-016-0407-4. 
14. Kadowaki T, Inagaki N, Kondo K, et al. Efficacy and safety of canagliflozin as add-on therapy to teneligliptin in Japanese patients with type 2 diabetes mellitus: results of a 24-week, randomized, doubleblind, placebo-controlled trial. Diabetes Obes Metab. 2017;19(6):874-82. https://doi.org/10.1111/ dom.12898.

15. Kadowaki $\mathrm{T}$, Inagaki N, Kondo $\mathrm{K}$, et al. Long-term safety and efficacy of canagliflozin as add-on therapy to teneligliptin in Japanese patients with type 2 diabetes. Diabetes Obes Metab. 2018;20(1):77-84. https://doi.org/10.1111/dom.13038.

16. Kidney Disease: Improving Global Outcomes (KDIGO). KDIGO 2012 Clinical Practice Guideline for the Evaluation and Management of Chronic Kidney Disease, Chapter 1: Definition and classification of CKD. Kidney Int Suppl. 2013;3(1):19-62. https://doi.org/10.1038/kisup.2012.64.

17. Kanda E, Kashihara N, Matsushita K, et al. Guidelines for clinical evaluation of chronic kidney disease: AMED research on regulatory science of pharmaceuticals and medical devices. Clin Exp Nephrol. 2018;22(6):1446-75. https://doi.org/10. 1007/s10157-018-1615-X.

18. Kaku K, Chin R, Naito Y, et al. Safety and effectiveness of empagliflozin in Japanese patients with type 2 diabetes: interim analysis from a post-marketing surveillance study. Expert Opin Drug Saf. 2020;19(2):211-21. https://doi.org/10.1080/ 14740338.2020.1694659.

19. Nakamura I, Maegawa H, Tobe K, Uno S. Real-world evidence for long-term safety and effectiveness of ipragliflozin in Japanese patients with type 2 diabetes mellitus: final results of a 3 -year post-marketing surveillance study (STELLA-LONG TERM). Expert Opin Pharmacother. 2021;22(3):373-87. https://doi.org/10.1080/14656566.2020.1817388.

20. Utsunomiya K, Koshida R, Kakiuchi S, et al. Safety and effectiveness of tofogliflozin in Japanese patients with type 2 diabetes mellitus treated in real-world clinical practice: results of a 36-month post-marketing surveillance study (J-STEP/LT). J Diabetes Investig. 2021;12(2):184-99. https://doi.org/ 10.1111/jdi.13333.

21. Hara H, Kim H, Tokimoto T, Takumi Y. Evaluation of safety and efficacy of dapagliflozin in patients with type 2 diabetes - a final report of a special drug use-results survey for long-term use (DAHLIA Study). Jpn Pharmacol Ther. 2020;48(8):1305-33 (In Japanese).

22. Engelhardt K, Ferguson M, Rosselli JL. Prevention and management of genital mycotic infections in the setting of sodium-glucose cotransporter 2 inhibitors. Ann Pharmacother. 2021;55(4):543-8. https://doi.org/10.1177/1060028020951928.

23. Inagaki N, Goda M, Yokota S, Maruyama N, Iijima H. Safety and efficacy of canagliflozin in Japanese patients with type 2 diabetes mellitus: post hoc subgroup analyses according to body mass index in a 52-week open-label study. Expert Opin Pharmacother. 2015;16(11):1577-91. https://doi.org/10. $1517 / 14656566.2015 .1055250$.

24. American Diabetes Association. 11. Microvascular complications and foot care: Standards of medical care in diabetes-2021. Diabetes Care. 2021;44(Suppl 1):S151-67. https://doi.org/10.2337/dc21-S011.

25. Tanaka $H$, Takano $K$, Iijima $H$, et al. Factors affecting canagliflozin-induced transient urine volume increase in patients with type 2 diabetes mellitus. Adv Ther. 2017;34(2):436-51. https://doi.org/10. 1007/s12325-016-0457-8.

26. Matthews DR, Li Q, Perkovic V, et al. Effects of canagliflozin on amputation risk in type 2 diabetes: the CANVAS Program. Diabetologia. 2019;62(6): 926-38. https://doi.org/10.1007/s00125-019-48398.

27. Perkovic V, Jardine MJ, Neal B, et al. Canagliflozin and renal outcomes in type 2 diabetes and nephropathy. N Engl J Med. 2019;380(24): 2295-306.

NEJMoa1811744.

28. Iwase M, Fujii H, Nakamura U, et al. Incidence of diabetic foot ulcer in Japanese patients with type 2 diabetes mellitus: The Fukuoka diabetes registry. Diabetes Res Clin Pract. 2018;137:183-9. https:// doi.org/10.1016/j.diabres.2018.01.020.

29. Neal B, Perkovic V, Mahaffey KW, et al. Canagliflozin and cardiovascular and renal events in type 2 diabetes. N Engl J Med. 2017;377(7):644-57. https://doi.org/10.1056/NEJMoa1611925.

30. Mahaffey KW, Neal B, Perkovic V, et al. Canagliflozin for primary and secondary prevention of cardiovascular events: results from the CANVAS Program (Canagliflozin Cardiovascular Assessment Study). Circulation. 2018;137(4):323-34. https:// doi.org/10.1161/circulationaha.117.032038.

31. Rådholm K, Figtree G, Perkovic V, et al. Canagliflozin and heart failure in type 2 diabetes mellitus: results from the CANVAS Program. Circulation. 2018;138(5):458-68. https://doi.org/10.1161/ circulationaha.118.034222.

32. Doi $Y$, Ninomiya $T$, Hata J, et al. Impact of glucose tolerance status on development of ischemic stroke and coronary heart disease in a general Japanese population: the Hisayama study. Stroke. 
2010;41(2):203-9. strokeaha.109.564708.

https://doi.org/10.1161/

33. Sone $\mathrm{H}$, Tanaka S, Tanaka S, et al. Serum level of triglycerides is a potent risk factor comparable to LDL cholesterol for coronary heart disease in Japanese patients with type 2 diabetes: subanalysis of the Japan Diabetes Complications Study (JDCS). J Clin Endocrinol Metab. 2011;96(11):3448-56. https://doi.org/10.1210/jc.2011-0622.

34. Ueki K, Sasako T, Okazaki Y, et al. Effect of an intensified multifactorial intervention on cardiovascular outcomes and mortality in type 2 diabetes (J-DOIT3): an open-label, randomised controlled trial. Lancet Diabetes Endocrinol. 2017;5(12): 951-64. 8587(17)30327-3.

35. Yokoyama H, Matsushima M, Kawai K, et al. Low incidence of cardiovascular events in Japanese patients with type 2 diabetes in primary care settings: a prospective cohort study (JDDM 20). Diabet Med. 2011;28(10):1221-8. https://doi.org/10.1111/ j.1464-5491.2011.03347.x.

36. Offurum A, Wagner LA, Gooden T. Adverse safety events in patients with chronic kidney disease
(CKD). Expert Opin Drug Saf. 2016;15(12): 1597-607. https://doi.org/10.1080/14740338.2016. 1236909.

37. Rothschild JM, Bates DW, Leape LL. Preventable medical injuries in older patients. Arch Intern Med. 2000;160(18):2717-28. https://doi.org/ 10.1001/archinte.160.18.2717.

38. Kashiwagi A, Maegawa H. Metabolic and hemodynamic effects of sodium-dependent glucose cotransporter 2 inhibitors on cardio-renal protection in the treatment of patients with type 2 diabetes mellitus. J Diabetes Investig. 2017;8(4): 416-27. https://doi.org/10.1111/jdi.12644.

39. Mudaliar S, Polidori D, Zambrowicz B, Henry RR. Sodium-glucose cotransporter inhibitors: effects on renal and intestinal glucose transport: from bench to bedside. Diabetes Care. 2015;38(12):2344-53. https://doi.org/10.2337/dc15-0642.

40. Ferrannini E, Solini A. SGLT2 inhibition in diabetes mellitus: rationale and clinical prospects. Nat Rev Endocrinol. 2012;8(8):495-502. https://doi.org/10. 1038/nrendo.2011.243. 